\title{
ИССЛЕДОВАНИЕ ПЕРЕДАЧИ ЦЕПНОЙ СВЯЗИ С МЕСТОИМЕНИЯМИ В РУССКО-КИТАЙСКОМ ПЕРЕВОДЕ
}

\section{RESEARCH OF TRANSMISSION OF CHAIN COMMUNICATION WITH LOCATIONS IN THE RUSSIAN-CHINESE TRANSLATION}

Li Mei

Summary: This work is devoted to the study of the translation of a chain connection with pronouns in the Russian-Chinese translation. Chain link is the most common link in the text. And in both Russian and Chinese, the replacement of pronouns is a very active means of chain communication for the text. In the process of Russian-Chinese translation, the main task of transmitting Russian pronouns is to ensure that the translated text matches the expressions of the Chinese language and avoids misunderstanding. This article provides examples of a chain connection with pronouns in certain texts and corresponding translations; generalization of pronoun translation methods, patterns in their use and principles of restriction on the choice of these methods. The content has been added to the main concepts and theories of text translation.

Keywords: chain connection; pronouns; anaphora; recovery; principles of limitation; Russian-Chinese translation.
$\mathrm{B}$ настоящее время исследование перевода ограничивается пониманием слов и предложений. С развитием лингвистики и углублением исследования перевода, переводчики стали обращать все больше и больше внимания на более крупную языковую единицу - текст.

Как известно, процесс перевода можно разделить на понимание и выражение текста. Связь между предложениями как один из главнейших признаков текста представляет собой основу понимания текста. До сих пор основное внимание уделялось пониманию текста, а не его выражению в переводе. Особого внимания заслуживают средства обеспечения связности в практике перевода, в результате чего перевод становится настолько же совершенным текстом, как и оригинал.

Данная работа основана на теории русского синтаксиста Г.Я. Солганика, который подразделил связь между предложениями в тексте на: (1) цепную связь, (2) параллельную связь, (3) присоединительную связь. [1] Цепная связь отражает в текущей речи процесс развития мысли, это самая распространённая связь в тексте. Средством цепной связи служит лексическое повторение, применение синонимов и замещение местоимениями. [2]

\author{
аспирант, Московский государственный университет \\ имени М.В. Ломоносова \\ limei19840721@126.com
}

Аннотация: Данная работа посвящена исследованию цепной связи с местоимениями в русско-китайском переводе. Цепная связь является самой распространённой связью в тексте. А как в русском языке, так и в китайском языке замена местоимениями является очень активным средством цепной связи для текста. В процессе русско-китайского перевода главная задача передачи русских местоимений в том, чтобы переводный текст соответствовал выражениям китайского языка и избежал непонимания. В данной статье приведены примеры цепной связи с местоимениями в определённых текстах и соответствующих переводах; обобщение методов перевода местоимений, закономерности при их использовании и принципов ограничения на выбор этих методов. Добавлено содержание к главным понятиям и теориям текстового перевода.

Ключевые слова: цепная связь; местоимения; анафора; восстановление; принципы ограничения; русско-китайский перевод.

Анафора местоимения и в русском языке, и в китайском является очень активным средством обеспечения связности текста. По мнению Г.Я. Солганика местоимение является самым популярным средством для этого. [2] Л.М. Лосева говорила, что если во втором предложении и не появится местоимение, оно будет самый минимум в третьем или в четвёртом предложении.[3] Ван Цаньлун считает: в системе согласования современного китайского языка личное местоимение "он" является одним из средств согласования самой высокой частоты использования. [4]

Данная работа посвящена исследованию выражения цепной связи посредством местоимений в русско-китайском переводе. Не все местоимения обладают анафорическими возможностями: такие местоимения как "кто"、"я"、“ты"、"никто"、"куда" не могут заменять знаменательные слова. Местоимения, указывающие на знаменательные слова можно разделить на четыре группы: 1) личные местоимения "он, она, оно, они", 2) притяжательные местоимения "его, её, их", 3) указательные местоимения со притяжательным значением "этот (сей), тот, такой, таков" и 4) указательное местоимение "это". Обычно считают, что в китайском языке только“他”, “她”, “它”, “他们”, “她们” (он, она, оно, они) и так далее некоторые местоимения имеют функцию анафоры, и они 
только ограничены третьем лицом. Так что Ван Цаньлун прямо писал, что местоимение “他(он)" символизирует остальные местоимения с функцией анафоры.

\section{1. В русско-китайском переводе методы передачи местоимений в шепной связи.}

В русском языке местоимений с функцией анафоры больше, чем в китайском языке, в результате чего их частота пользования тоже выше, чем в китайском языке. Поэтому в процессе перевода с русского на китайский некоторые русские местоимения трансформируются в другие слова. На практике существуют четыре метода передачи местоимений при указании цепной связи, это сохранение, эллипсис, замена и восстановление [5].

В случае "сохранения" русское местоимение прямо передаётся соответствующим китайским местоимением. Например:

1. Ничего не ловилось, но Сергей Иванович не скучал и казался в самом весёлом расположении духа. Левин видел, что, раззадоренный разговором с доктором, он хотел поговорить.

谢尔盖·伊万诺维奇一无所获, 但并不感到无聊, 而且情绪很好。列文看出他同医生谈得津津有 味, 还想再谈谈。[6]

Когда существительное в единственном числе имеет обобщённое значение, при переводе, в виду отсутствия в китайском языке категории числа существительных, местоимение единственного числа заменяется местоимением множественного числа. Например:

2. Женщина хочет иметь право быть независимою, образованною. Она стеснена, подавлена сознанием невозможности этого.

перевод 1: 妇女渴望得到独立和受教育的权利。要 是想到不能获得这种权利, 她们会觉得委屈和难 受的。[6]

Если перевести этот пример обратно с китайского на русский, получится следующий текст (подобные переводы приводятся по необходимости для понимания устройства китайских фраз в случае существенного отличия от русских):

Женщины жаждут обрести право на независимость и получение образования. Если [они] думают, что не могут получить это право, они могут почувствовать стеснение и подавленность.

Из обратного перевода видно, что местоимение "она" заменено на "они", простое предложение превратилось в сложное и только в этом случае актуальное членение русского предложения соответствует логике китайского языка. Целесообразно привести и другие переводы это- го отрывка:

перевод 2: 妇女就是要得到自主的权利和受教育的权 利。妇女意识到不能得到这样的权利, 是感到委屈, 感 到不平的。[7]

(...Женщины сознают, что они не могут получить такое право и чувствуют себя стесненными, чувствуют несправедливость.)

перевод 3: 女人想要有独立的权利和受教育的权 利。她们觉得委屈、压抑, 因为她们意识到这是不可能 的。[6]

(...ни чувствуют стеснение и подавленность из-за того, что сознают, что это невозможно.)

перевод 4: 妇女渴望拥有独立和受教育的权利。她们 由于意识到这是办不到的而感到压抑。[9]

(...ни от сознания невозможности этого чувствуют угнетение.)

Видно большинством переводчиков тоже разделено придаточное предложение и перед придаточным предложением добавили субъект“她们(они)". Четвёртый перевод почти буквально передаёт русский текст, но он неуклюж и нарушает нормы китайского языка.

В случае "эллипсиса" для соблюдения норм китайского языка при переводе русское местоимение опускается. Например:

3. Вронский ничего и никого не видал. Он чувствовал себя царем не потому, что он верил, что произвел впечатление на Анну, он ещё не верил этому, —но потому, что впечатление, которое она произвела на него, давало ему счастье и гордость.

符朗斯基目空一切, 觉得自己是帝王。这并非 出于自信给安娜留下了印象一一他还不敢这么 想——而是因为她给他留下的印象使他感觉到幸 福和骄傲。[10]

(Вронский ничего не видел, чувствовал себя царем. Это происходило не из-за того, что [он] ${ }^{(1)}$ верил, что произвел на Анну впечатление-он ${ }^{(2)}$ ещё не осмеливался так думать, - а из-за того что произведенное ею(3) на него ${ }^{(4)}$ впечатление позволяло ему ${ }^{(5)}$ чувствовать счастье и гордость.)

В случае "замены" для соблюдения правильности китайского текста при переводе русское местоимение замещается синонимом, при этом его синтаксическая функция сохраняется. Например:

4. Место же, где он уже ничего не мог сказать и мялся, и резал стол, и качался на стуле, было то, где ему надо было сказать о допотопных патриар- 
$\underline{\mathbf{x a x}}$. Из них он никого не знал, кроме Еноха, взятого живым на небо.

到了他什么也说不上来的那个地方, 便不知怎么 办好地又用小刀刻桌子又摇晃椅子, 那是在他应 当说出太古洪荒时代的长老们。除了一个厄诺 士, 那些人中活着上升到天国的, 他一个也说不 上来。 $[10]$

(...Кроме Еноха, взятого (взятых) из тех людей живым (живыми) на небо он ни одного не знал.)

В случае "восстановления" русское местоимение в переводе замещается повторением объекта, на который оно указывает. Например:

5. Для меня одно и одно - это твоя любовь. Если она моя, то я чувствую себя так высоко, так твёрдо, что ничто не может для меня быть унизительным.

对于我来说, 你的爱情是一切的一切。我有了你 的爱情, 就觉得自己十分高尚, 十分刚强, 一点 也没有什么窝囊的。[7]

Эти четыре метода- сохранение, эллипсис, замена и восстановление имеют свои особенности и свои функции, они органически переплетены и вместе связывают предложения в цельный текст.

\section{2. Приншипы ограничения по анафоре местоимения в китайском языке.}

Как правило, в начале текста обычно используются имена существительные, обозначающие человека или предмет, потом текст связывается анафорой местоимений или нулевой анафорой. Но это только обычное правило, на самом деле текст-очень сложная система, средства анафоры также подвержены ограничениям. Ши Тэцян, сравнивая типы анафоры местоимений в русском и китайском тексте, уделил большое внимание анализу разных факторов, ограничивающих использование местоимений. [11] Он считает, что в русском тексте чаще, чем в китайском используются местоимения, указывающие на имена существительные. Причину этого он видит в том что с одной стороны в русском языке в функции анафоры используется большее число местоимений, чем в китайском, а с другой стороны, указанные объекты, грамматика, стилистика и другие факторы также ограничивают возможности на пользования местоимений китайского языка для различения смысла русского текста.

Ли Баолин исследовал в русском тексте трансляцию цепной связи, оформленной личными местоимениями "он (она, оно, они)". По данным его статистического анализа местоимения сохраняют в $88 \%$ случаев. В остальных случаях изменения бывает трёх типов- это восстановление, эллипсис и замена. Среди них восстановление употребляется гораздо чаще других и составляется 52\%, замена употребляется реже всего. [5] Главными элементами, влияющими на передачу местоимений, являются роль местоимения в предложении и вид объектов, на тот они указывают. В этой статье мы специально остановимся на сохранении, эллипсисе и замене местоимений в русско-китайском переводе, в особенности на анализе самого распространённого способа трансформации местоимений - восстановлении.

Во-первых, на трансляцию русских местоимений оказывают большое влияние объекты указания местоимениями. В цепной связи с местоимениями "он (она, оно, они)", их объекты указания можно разделить на антропонимы и обычные существительные, а последние дополнительно разделяются на обозначения людей и предметов.

\section{1 Местоимение указывает на человека.}

Когда в контексте появляются больше двух героев, особенно разного пола, для того чтобы избежать нечёткого указания в китайском языке не используются местоимения, заменяющие героев, а повторяются их имена тех самых людей, за счёт чего и достигается связность предложений.

6. Виктор и Анна - муж и жена. Он работает на заводе, аона - в школе.

维克多和安娜是夫妻。维克多在工厂上班, 在学校里工作。[12]

7. И она покраснела за отца. Он тотчас же понял это и так же покраснел.

她为父亲脸红。父亲立刻觉察了, 脸也红了。 6

Почему в таких ситуациях в китайском тексте не употребляется анафора местоимения? Причина этого мы видим во-первых в том, что китайские слова“他(он)"', 她 (она)" являются омофонами. Во-вторых, когда в начальном предложении одно из двух имён существительных, обозначающих людей, не является субъектом действия, его надо повторить, а не заменять на местоимение. Этого грамматического явления мы коснёмся ниже, обсуждая ориентированность на подлежащее.

\section{2 Местоимение указывает на предметы.}

В китайском языке неагентивное неодушевлённое подлежащее не может заменяться местоимением. Например, на вопрос: "信来了吗? (Пришло ли письмо?)", следует отвечать: “信来了。(Письмо пришло.)”, а не: “ 它来了。(Оно пришло.)". Поэтому предметно-личное местоимение русского языка употребляется шире, чем местоимение китайского языка "它", и в китайском языке необходимо использовать повторение слов, там, где в русском можно применять местоимения. Например: 
8. Точность и краткость - вот первые достоинства прозы. Она требует мыслей - без них блестящие выражения ни к чему служат. (А.С.Пушкин)

перевод 1: 准确而简练是散文的首要优点。她要 求有见解, 没有思想观点, 华丽的表达便一无是 处。

перевод 2: 准确而简练, 是散文的最大优点。 散文需要有思想, 否则, 华美的语句便毫无用 处。[5]

Это типичная цепная связь с местоимениями. Первый перевод игнорирует различие между местоимениями русского и китайского языка: в русском языке личное местоимение "она" может как заменять человека, так и заменять предмет, а в китайском языке местоимение “她 (она)" только указывает на человека. Если бы в переводе местоимение сохранилось и вызвало бы непонимание.

Приведём ещё примеры:

9. Из холма...бежала вода. Она падала на землю...( А.Чехов )

......小山里流出水来。水落到地面上......[12]

10. Он...перевернул свечу огнём вниз. Она с треском потухла. ( Л.Толстой )

他……把蜡烛翻过来, 让火花朝下。蜡烛爆了一 下，就熄灭了。[12]

11. Теперь при свете лампочки можно было разглядеть его улыбку; она была очень сложной... (А.Чехов)

现在, 借了灯光, 可以看清楚他的笑容了; 那笑 容是很复杂的......[12]

Когда в контексте появляется несколько предметов, или люди и вещи, даже в том случае, если субъектом не является вещь, в китайском языке всё-таки используется повторение слов, а не замена местоимением.

12. Наконец однажды утром Савельич вошёл ко мне, держа в руках письмо. Я схватил его с трепетом. (А.Чехов)

\section{终于有一天早上萨维奇手捧着一封信走进我的房 间。我颤抖着抓过信来。[12]}

13. Но после вашего слова я приму вновь мою бедность, я с радостью стану переносить отчаянное положение моё. Я встречу борьбу, я рад буду ей, я воскресну в ней с новыми силами!

但是有了您这句话, 我将重新忍受我的贫穷, 我 将乐于承受我的绝境。我将迎接斗争, 我还乐 于去斗争, 我要以新的力量投入斗争并获得新 生! [13]

Дословно: “...Я с новыми силами брошусь в борьбу и обрету [в ней] новую жизнь."

\section{3 Анафора местоимений ограничена синтаксисом.}

Ориентированность на подлежащее-характерная черта анафоры китайского языка. Ван Цаньлун считал, когда находящиеся в начальном предложении дополнение или определение становятся темой дальнейшего предложения, независимо от того, насколько близко по расстоянию они находятся от подлежащего предыдущего предложения, они обозначаются посредством имени существительного, а не местоимением. [4] Большинство предыдущих примеров демонстрирует это правило. В примере 7) “父亲(отец)" в начальном предложении не быть подлежащее, для связности текста в дальнейшем предложении указывающее на него только повторение слова “父亲(отец)", одновременно видно что в русском предложении этого примера не используется анафора имени существительного, а анафора местоимения "он", это имеется в виду русский язык не ограничен этим правилом.

Исследование Ли Баолин показало, что при цепной связи случаи сохранения местоименной анафоры подлежащего составляют 93\%, а местоименной анафоры дополнения 70\%. [5] Например:

14. Книга эта после тщательной отделки была издана в прошлом году и разослана книгопродавцам. Ни у кого не спрашивая о ней, неохотно и притворноравнодушно отвечая на вопросы своих друзей о том, как идёт его книга, не спрашивая даже у книгопродавцев, как покупается она, Сергей Иванович зорко, с напряженным вниманием следил за тем первым впечатлением, какое произведёт его книга в обществе и в литературе.

这部著作经过仔细修订, 去年已正式出版, 并且 分发到书商手里。谢尔盖 - 伊万诺维奇没向任何 人提到这本书, 朋友们问他, 他都回答得很淡 漠，他从不向书商打听书的销路，其实他十分关 心这部著作给社会和学术界的最初印象。[6]

(Это произведение, подвергнувшись тщательной отделке, в прошлом году уже было официально издано, а также распространено книготорговцам. Сергей Иванович никому не упоминал эту книгу, [когда] друзья его спрашивали, он всегда отвечал равнодушно, он никогда не спрашивал у книготорговцев о сбыте этой книги, но он в высшей степени заботился о первых впечатлениях, которые это произведение вызовёт в обществе и научных кругах.)

\section{3. Указательные местоимения заменяют имя сушествительное.}

В русском языке указательные местоимения "этот" и "тот" заменяют имена существительные и связывают сложные предложения. По способу их использования 
они близки к личным местоимениям, но они обычно замещают названия людей или животных в косвенных падежах. В китайском языке эти местоимения отдельно не используются, а указательное местоимение “那个(тот)" играет вспомогательную роль при повторении существительных. Например:

15. Она зажмурилась в улыбке и, вспомнив о Танечке, пошла её будить, хотя та как будто бы и не спала... (Г. Семенов)

她笑得眯起了眼睛, 于是想起了塔涅琪卡, 就去唤 醒她, 其实塔涅琪卡似乎根本没睡......[11]

В примере русского языка указательное местоимение употребляется как средство замены и связывает текст, а в переводе на китайский язык принимается повторение самого имени существительного. Почему в русском предложении употребляется "тот (та)", а не "он (она)"? И почему в китайском переводе употребляется повторение указанного имени существительного, а не посредством анафоры местоимения? Причина в том, что в примере оказалось два человека одинакового пола (она и Танечка), и при использовании местоимений "она" или “她(она)" было бы непонятно на кого они указывают. Однако в русском языке кроме личных местоимений “он (она)" ещё имеются указательные местоимения "тот (та)", которые как раз указывают на имена существительные в косвенных падежах, таким образом отказ от повторения имён существительных и не вызывание непонимания.

16. Он глядел своим воспаленным взглядом прямо в глаза генералу, как бы даже желая, чтобы тот прочел в его взгляде всю его мысль.

他用激狂的目光直逼着将军的眼睛, 仿佛希望将 军在他的目光中看出他的全部思想。[13]

17. Вдруг он подошёл к князю; тот в эту минуту стоял опять над портретом Настасьи Филипповны и рассматривал его.

\section{突然他走近公爵, 而公爵此时又站在纳斯塔西娅・} 费利帕夫娜的肖像前, 端详着它。[13]

18. Лекарь шепнул девке, та бросилась в переднюю, растолкала Степана, тот побежал будить Гаврилу, Гаврила сгоряча велел поднять весь дом.

郎中跟一个女佣人小声地讲了几句话, 她立刻跑 到前厅去, 摇醒了歁捷潘, 斯捷潘又跑去叫醒加 夫里拉, 加夫里拉一生气, 就吩咐把整个宅子里 的人都叫起来。[14]

Использование указательного местоимения "этот" немного отличается от применения местоимения "тот": имя существительное указанное словом "этот" может быть и в именительном падеже, и в косвенных падежах, но при переводе на китайский нужно после слова “这个 (этот)" добавить то самое указанное имя существительное. Например:

19. Идёт другой самолёт. Немцы сегодня упорны.
Этот вертится над районом, как бы ища минуту, когда будет перерыв стрельбы. (Н.Тихонов.)

又来了另一架飞机。德国人今天很顽固。这架飞 机在地区上面盘旋, 似乎在寻找地面炮火停息的片 刻。[11]

Из этого примера видно, что в русском языке можно только использовать указательное местоимение "этот" и заменяющее объект, а в этой ситуации в китайском языке нужно после указательного местоимения (这个) восстановление самого указанного объекта. Ещё нужно подчеркнуть, что в русском тоже часто используется конструкция анафоры "этот + имя существительное", и частота её появления намного больше. По отдельности как средство анафоры, "тот" употребляется чаще, чем "этот".

В русском языке в качестве средства обеспечения связности текста также может использоваться порядковое числительное. Для применения порядковых числительных число упомянутых в тексте людей (вещей) должно быть два или больше. В китайском в таких случаях также используется повторение имён существительных. Например:

20. В бричке сидело двое N-ских обывателей: N-ский купец Иван Иваныч Кузьмичов.., и другой-отец Христофор Сирийский...Первый о чем-то сосредоточенно думал и встряхивал головой, чтобы прогнать дремоту...второй же влажными глазками удивленно глядел на мир божий...(А.Чехов)

\section{车上坐着 $\mathrm{N}$ 城的两个居民:一个是 $\mathrm{N}$ 城的商人，名 叫伊万・伊万内奇・库茨米乔夫……, 还有一个 是神父克利斯托佛尔・西利斯基……商人在想心 事, 并一个劲摇头, 想赶走睡意……神父呢, 正 用他那湿润的小眼睛惊奇地望着上帝的世界…… [12]}

Из вышесказанного можно сделать вывод о том, что как в русском языке, так и в китайском языке замена на личные местоимения является наиболее распространённым способом обеспечения цепной связи. В русском языке видов местоимений с функцией анафоры больше, чем в китайском языке, в результате чего китайский перевод не может точно соответствовать русскому тексту. Тематичность и агентивность заменяемых объектов, отсутствие категории рода и синтаксические ограничения также сужают сферу использования местоимений китайского языка. Так что в практике русско-китайского перевода достаточно часто приходится прибегать к методу восстановления. В русском языке указательные местоимения и порядковые числительные тоже могут заменять имена существительные и связывать сложные предложения, что исключено для китайского языка. 


\section{ЛИТЕРАТУРА}

1. Солганик Г.Я. (Перевод Гу Сяцзюня). Синтаксическая стилистика русского языка. Шанхай: Шанхайское издательство об образовании иностранных языков, 1989. С. 46

2. Солганик Г.Я. От слова к тексту . М.: Просвещение, 1993.

3. Лосева. Л.М. Как строится текст. М.: Просвещение, 1980.

4. Ван Цаньлун. Исследование анафорической функции личного местоимения «он»//Китайская филология, 2000 (3).

5. Ли Баолин. 0 трансляции цепной связи с местоимениями в русско-китайском переводе// Университета иностранных языков Народно-освободительной армии /магистерская диссертация. 2006 (1).

6. Лев Толстой. (Перевод Цао Ина). Анна Каренина. Шанхай: Шанхайское переводческое издательство, 1989.

7. Лев Толстой.(Перевод Ли Гана). Анна Каренина. Ханчжоу: Чжэцзянское литературно-художественный издательство, 1992.

8. Лев Толстой.(Перевод Чжи Ляна). Анна Каренина. Нанкин: Издательство Илин, 1996.

9. Лев Толстой.(Перевод Чжоу Яна). Анна Каренина. Пекин: Издательство жэйминьвэньсюэ чубаньшэ, 2000.

10. Лев Толстой. (Перевод Изинь Гэ). Анна Каренина. Сиань: Шэньсиское Народное издательство, 1998.

11. Ши Тэцян. Сравнение анафоры местоимений в русском и китайском тексте //Исследование иностранных языков, 2001 (4).

12. Ши Тэцян. Сравнение текстовой связности в русском и китайском тексте //Преподавание русского языка в Китае, 1997 (1).

13. Ф.М. Достоевский. (Перевод Ши Госюна). Идиот. Сиань: Издательство Сиань Цзяотун, 2016.

14. И.С. Тургенев. (Перевод Ба Цзиня). Муму. Пекин: Издательство Народной Литературы, 1988.

\section{○ Ли Мэй (limei19840721@126.com).}

Журнал «Современная наука: актуальные проблемы теории и практики»

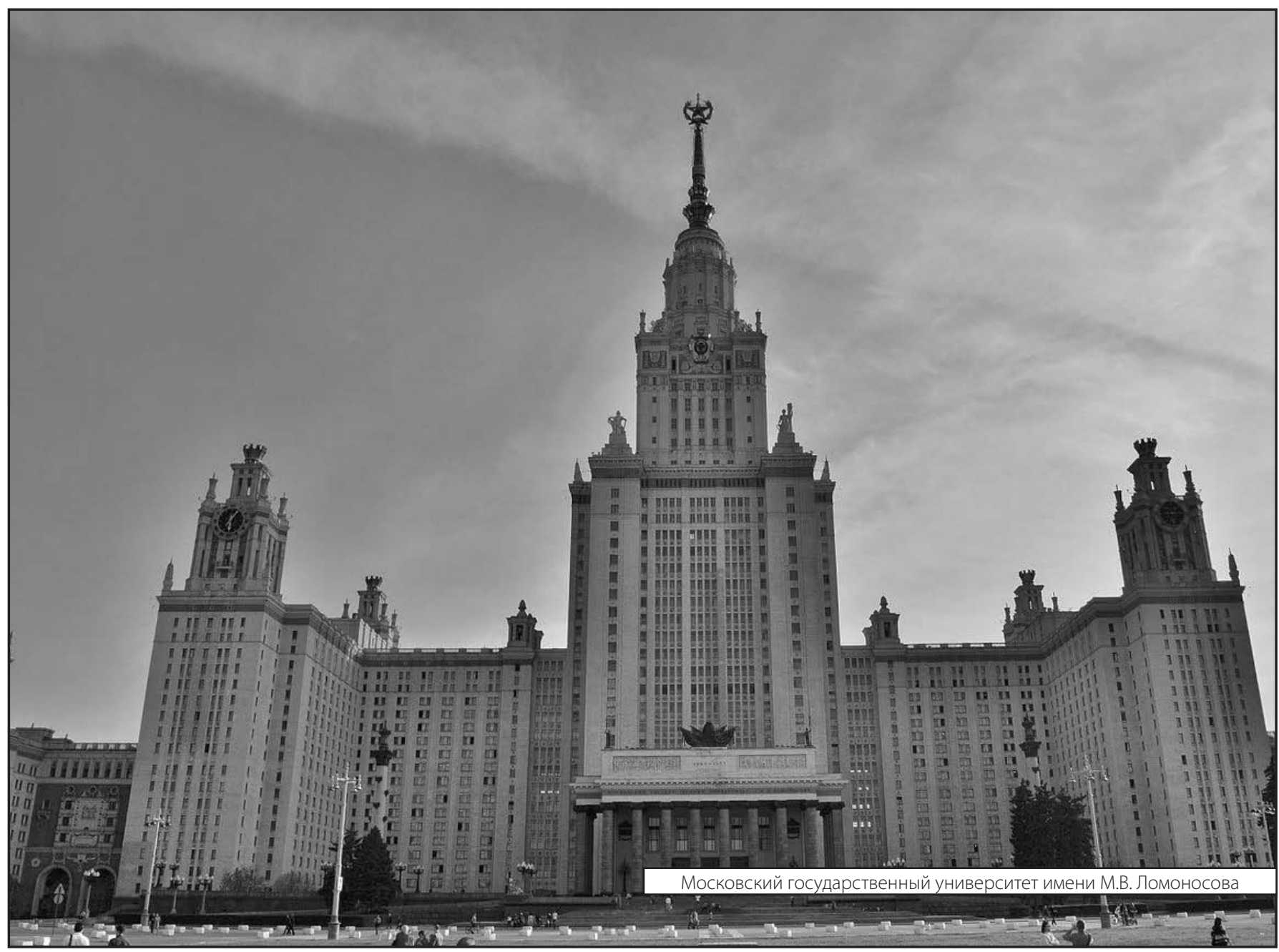

